\title{
Commentary: Managing Thoracic Aortic Aneurysm in Patients with Bicuspid Aortic Valve Based on Aortic Root-Involvement
}

\author{
Marco Russo*, Paolo Nardi, Guglielmo Saitto, Fabio Bertoldo and Giovanni Ruvolo \\ Department of Cardiac Surgery, Tor Vergata University of Rome, Rome, Italy
}

Keywords: bicuspid valve, ascending aorta, aortic root, valve sparing, genetic syndromes

\section{A commentary on}

Managing Thoracic Aortic Aneurysm in Patients with Bicuspid Aortic Valve Based on Aortic Root-Involvement

by Norton, E., and Yang, B. (2017). Front. Physiol. 13:397. doi: 10.3389/fphys.2017.00397

OPEN ACCESS

Edited by:

Zhongkui Hong,

University of South Dakota,

United States

Reviewed by:

Hanrui Zhang,

Columbia University, United States

*Correspondence:

Marco Russo

mar.russo1987@gmail.com

Specialty section:

This article was submitted to

Vascular Physiology

a section of the journal

Frontiers in Physiology

Received: 09 August 2017 Accepted: 09 October 2017

Published: 30 October 2017

Citation:

Russo M, Nardi P, Saitto G, Bertoldo F and Ruvolo G (2017) Commentary: Managing Thoracic Aortic Aneurysm in Patients with Bicuspid Aortic Valve Based on Aortic Root-Involvement.

Front. Physiol. 8:838.

doi: 10.3389/fphys.2017.00838
We read with great interest the paper from Norton and Yang (2017) in which they optimally described their philosophy in the treatment of patients affected by concomitant bicuspid aortic valve and thoracic aorta dilation. They described an interesting tailored approach based on the involvement of aortic root: an aggressive surgical resection for diameter larger than $50 \mathrm{~mm}$ is proposed in case of root dilation associated with aortic insufficiency (Cluster A; malignant form) whereas a less precocious aortic resection (diameter $>55 \mathrm{~mm}$ ) for "cluster B" patients, defined as no root dilation but with ascending aorta enlargement (benign form).

Patients affected by bicuspid aortic valve aortophaty represent a heterogeneous population in which both genetics and hemodynamic factors play a special role in the pathogenesis of proximal aorta dilation (Veldtman et al., 2006; Michelena et al., 2008; Della Corte et al., 2014).

In this brief commentary we would like to focus on a particular subgroup of patients, that we would like to define as "modified Cluster B": in this population the dilation of ascending aorta represents the indication for operation in presence of a normally functioning bicuspid aortic valve and not dilated root. These patients represent a very rare cohort in which the cardiac surgeon should manage the possibility to preserve a not-malfunctioning but congenitally altered valve and with not enlarged bicuspid Sinues of Valsalva.

In our recently published data (Russo et al., 2017) on 47 patients (mean age $57 \pm 11$ years, 31 males) treated in a 20 -years period, we reported a very low risk of reoperation on spared aortic root with an actuarial freedom reoperation of 100 and $94.4 \pm 5.6 \%$ at 5 and 10 years. No significantly enlargement of Sinuses was recorded in echo assessment and no new acute aortic syndromes occurred. Moreover, the requirement for a reoperation during the follow-up period was determined by leaflet pathology in presence of still normal root. We assessed that, even in the setting of a bicuspid aortic root, the treatment of a cluster B patient with normally functioning valve and not enlarged Sinues is a safe and valuable option (Russo et al., 2017). Moreover we observed that this particular aortic dilation phenotype is associated with type $0 \mathrm{BAV}$ with antero-posterior orientation. Maybe this association described a particular subcategory with a genetic substrate not yet completely understood. 
What we would like to know is the Author's experience when faced with a similar situation of "modified Cluster B" patients.

What could we learn more in the field of bicuspid aortic valve syndrome?

\section{REFERENCES}

Della Corte, A., Body, S. C., Booher, A. M., Schaefers, H. J., Milewski, R. K., Michelena, H., et al. (2014). Surgical treatment of bicuspid aortic valve disease: knowledge gaps and research perspectives. J. Thorac. Cardiovasc. Surg. 147, 1749-1757. doi: 10.1016/j.jtcvs.2014. 01.021

Michelena, H. I., Desjardins, V. A., Avierinos, J. F., Russo, A., Nkomo, V. T., Sundt, T. M., et al. (2008). Natural history of asymptomatic patients with normally functioning or minimally dysfunctional bicuspid aortic valve in the community. Circulation 117, 2776-2784. doi: 10.1161/CIRCULATIONAHA.107.740878

Norton, E., and Yang, B. (2017). Managing thoracic aortic aneurysm in patients with bicuspid aortic valve based on aortic root-involvement. Front. Physiol. 13:397. doi: 10.3389/fphys.2017.00397

Russo, M., Saitto, G., Nardi, P., Bertoldo, F., Scafuri, A., Bassano, C., et al. (2017). Bicuspid aortic root spared during ascending aorta surgery: anupdate

\section{AUTHOR CONTRIBUTIONS}

$\mathrm{MR}$ is the main investigator. PN was responsible of data analysis. GS participated to data collection of follow up. FB was responsible of data collection. GR was coordinator.

of long-term results. J. Thorac. Dis. 9, 1634-1638. doi: 10.21037/jtd.2017. 05.83

Veldtman, G. R., Connolly, H. M., Orszulak, T. A., Dearani, J. A., and Schaff, H. V. (2006). Fate of bicuspid aortic valves in patients undergoing aortic root repair or replacement for aortic root enlargement. Mayo Clin. Proc. 81, 322-326. doi: $10.4065 / 81.3 .322$

Conflict of Interest Statement: The authors declare that the research was conducted in the absence of any commercial or financial relationships that could be construed as a potential conflict of interest.

Copyright (C) 2017 Russo, Nardi, Saitto, Bertoldo and Ruvolo. This is an open-access article distributed under the terms of the Creative Commons Attribution License (CC $B Y)$. The use, distribution or reproduction in other forums is permitted, provided the original author(s) or licensor are credited and that the original publication in this journal is cited, in accordance with accepted academic practice. No use, distribution or reproduction is permitted which does not comply with these terms. 